\title{
Comparison of strength and stiffness parameters of purlins with different cross-sections of profiles
}

https://doi.org/10.1515/eng-2020-0061

Received Jul 15, 2019; accepted Apr 29, 2020

\begin{abstract}
The article presents comparative analyzes aimed at determining the optimal cross-section used in coldformed steel purlins. The geometrical characteristics, bending resistance and self-weight of channel, zeta and hat cross-sections were compared. The calculations were made using Dlubal SHAPE-THIN software for the bending by the main axis y-y and z-z. The characteristics for the gross and effective cross-section were determined. Based on the first stage analyzes, a significant decrease in crosssectional bending resistant was observed as a result of a local buckling. The solution to this problem may be the use of intermediate stiffeners. In the second stage, analysis of the impact of the intermediate stiffeners' locations on the characteristics of hat sections were conducted. Additional intermediate stiffeners on the webs, on the upper chord, and on the webs and upper chord (together) were considered. A significant effect on the bending resistant with a small increase in the element's self-weight has been demonstrated. In the third stage, the characteristics of a channel, zeta and hat profile with intermediate longitudinal stiffener in the middle of the web were compared. The performed analyzes demonstrated that the hat crosssection shows a significant advantage in bending by the main axis z-z. This advantage can be used in case of lack of protection against lateral torsional buckling and a larger degree of roof slope.
\end{abstract}

Keywords: steel structures, cold formed profiles, purlins, channel sections, zeta sections, hat sections

\footnotetext{
*Corresponding Author: Andrzej Wojnar: Rzeszów University of Technology, Faculty of Civil and Environmental Engineering and Architecture, ul. Poznańska 2,35-084 Rzeszów, Poland; Email: awojnar@prz.edu.pl

Katarzyna Sieńkowska: Rzeszów University of Technology, Faculty of Civil and Environmental Engineering and Architecture, ul. Poznańska 2,35-084 Rzeszów, Poland; Email: k.sienkowska@prz.edu.pl
}

ə Open Access. @ 2020 A. Wojnar and K. Sieńkowska, published by De Gruyter Attribution 4.0 License

\section{Introduction}

In typical structure of steel single story industrial building purlins are usually members in roof structure used as a support of the roof decking or sheeting. In classical solutions they are made of hot-rolled sections (IPE) but recent developments in the field of construction aims at decrease self-weight of members by the using the cold-formed section (zeta section, channel section), which are described in [1-3] and [4] or [5]. Making of new types of cold formed profiles is caused by the development of technology of fabricate thin walled structures and the freedom in the shaping of cross-section. Difficulties appear due to complicated calculating procedures used for the verifications of limit states of thin-walled constructions. Members with slender cross-section plates in bending and axial compression are prone to local buckling, which must be considered in calculating of effective section properties. These characteristics are determined according to [6]. However, these are quite laborious and time-consuming iterative calculation procedures. The calculations recommended by the Eurocode procedure are as follows:

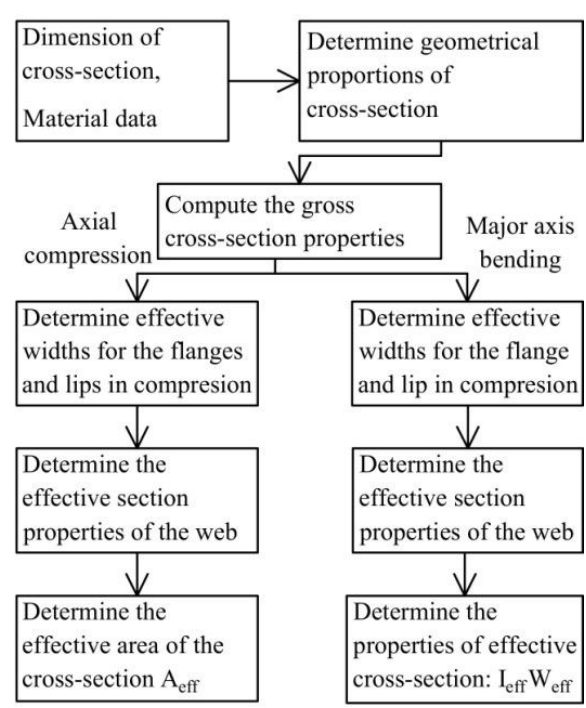

Figure 1: Flow chart: Calculation of effective section properties according to EC-1993-1-3 This work is licensed under the Creative Commons 
The technology of the production enables the increase of the stability of cross-section plates by changes in the geometry of the section for purposes of the increase of the efficiency of the material consumption, [7, 8] and [9]. Beneficial solution is the introduction of additional bends and groove as an intermediate and edge stiffeners. In this paper issues concerning design of cold-formed purlin with hat cross-sectional without stiffeners, with flange stiffeners and with together web and flange stiffeners are presented. The implementation of these stiffeners is aimed at:

- stiffening of the walls of the element,

- changing the cross-sectional class of the element to a more favorable one,

- increase (slightly) the cross-sectional area of the element.

Changing the geometric characteristics of the crosssection is very important taking into account checking its resistance and stability of the element. In order to determine the abovementioned characteristics, computer aided design methods were used - what was described in the article. The SHAPE-THIN computer software was used to facilitate and accelerate calculations and analyzes. Computer aided calculations also enabled the transfer of computational models and calculation results in electronic form to other kinde of software. The article also aims to promote computer calculations based on Fine Element Analysis, as a complement to and in some cases alternatives to manual calculations - performed using classical methods. Computer methods in the design and analysis of cold-bent components have been flavored recently. Currently, there are more and more softwares for this type of analysis, and their use in this article is proof of this. The calculations were carried out according to the following scheme:

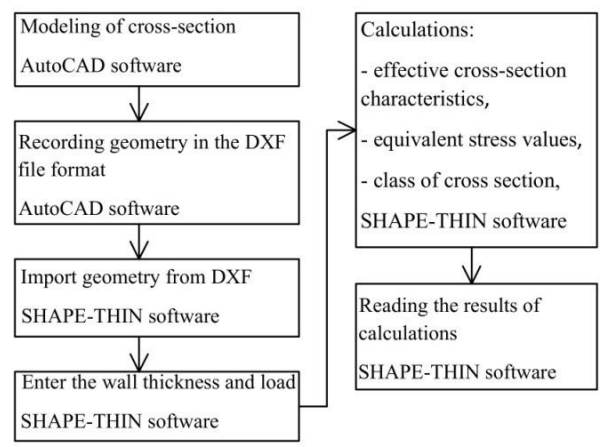

Figure 2: Flow chart: Calculation of effective section properties using AutoCad and SHAPE-THIN software

\section{Analysis of the cross-sections of elements}

\subsection{Analysed cross-section}

Cold-formed purlins are often made using zeta and channel profiles. These types of profiles are easy to produce and their self-weight is relatively small compared to hotrolled members. To disadvantages of these elements can be counted relatively low resistance in bending by the main axis $\mathrm{z}-\mathrm{z}$ of cross-section and vulnerability to local buckling (sections class 4). As an alternative to zeta and channel profiles can be used hat profiles. Though their mass is greater than zeta and channel profiles, their bending strength by the main $\mathrm{z}-\mathrm{z}$ axis of cross-section is much more than earlier elements. To compare geometrical characteristics and resistance of profiles with hat, channel and zeta cross-section, Figure 3 and Table 1, computational analysis were carried out.

a)

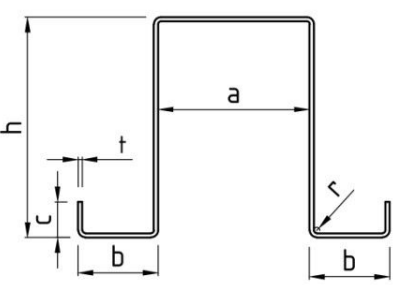

b)

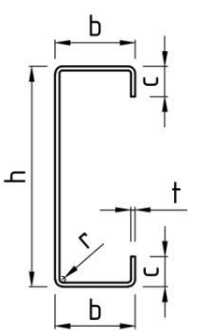

c)

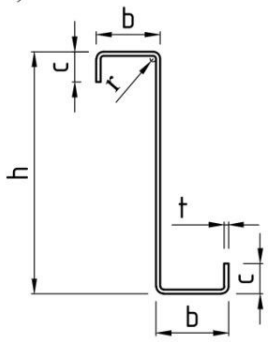

Figure 3: View of cold-formed non stiffened cross-section: a) hat profile, b) channel profile, c) zeta profile

Table 1: Dimensions of analysed profiles

\begin{tabular}{ccccc}
\hline Name & & $\begin{array}{c}\text { hat } \\
\text { profile }\end{array}$ & $\begin{array}{c}\text { U- } \\
\text { profile }\end{array}$ & $\begin{array}{c}\text { zeta } \\
\text { profile }\end{array}$ \\
\hline Height & $\mathrm{h}[\mathrm{mm}]$ & 200 & 200 & 220 \\
Upper chord & $\mathrm{a}[\mathrm{mm}]$ & 140 & - & - \\
Bottom chord & $\mathrm{b}[\mathrm{mm}]$ & 70 & 70 & $55 / 63$ \\
Stiffener & $\mathrm{c}[\mathrm{mm}]$ & 30 & 25 & 25 \\
Sheet thickness & $\mathrm{t}[\mathrm{mm}]$ & 2 & 3 & 2 \\
Internal radius & $\mathrm{r}[\mathrm{mm}]$ & 2,63 & 2,63 & 2,63 \\
\hline
\end{tabular}


The following parameters were obtained during calculations:

- the area of the gross cross-section Agross,

- class of cross-section in bending by the main axis y$\mathrm{y}$,

- section modulus of the gross cross-section with regard to the $\mathrm{y}$-y axis $\mathrm{W}_{y, e l}$,

- section modulus of the effective cross-section with regard to the $\mathrm{y}$-y axis $\mathrm{W}_{y, \text { eff }}$,

- resistance of cross-section in bending by the main axis $\mathrm{y}-\mathrm{y} \mathrm{M}_{R d, y, e f f}$,

- class of cross-section in bending by the main axis z-z

- section modulus of the gross cross-section with regard to the $\mathrm{z}-\mathrm{z}$ axis $\mathrm{W}_{z, e l}$,

- section modulus of the effective cross-section with regard to the $\mathrm{z}-\mathrm{z}$ axis $\mathrm{W}_{z \text {,eff }}$,

- resistance of cross-section in bending by the main axis z-z $\mathrm{M}_{R d, z, e f f}$.

\subsection{Computational analysis}

\subsubsection{Comparison of geometrical characteristics of hat, zeta and channel profiles}

All calculations were made using Dlubal SHAPE-THIN software, [10]. The computer software SHAPE-THIN determines section properties of open and closed thinn-walled cross-section and performs the stress analysis. Main features of the software:

- modeling of the cross-section via elements, sections, arcs and point elements,

- expandable library of material properties, yield strengths, and limit stresses,

- possibility obtaining of section properties of open, closed or non-connected cross-sections,

- possibility calculating effective properties of crosssections consisting of different materials,

- possibility determinating of weld stresses in fillet welds,

- stress analysis and design of cross-sections taking into account influence of primary and secondary torsion,-

- checking of (c/t) ratios,

- possibility calculating of effective cross-sections according to [11],

- classification of elements cross-section according to [12].

SHAPE-THIN calculates all relevant cross-section properties, including plastic limit forces and moments. In addition to the elastic stress analysis, you can perform the plastic analysis taking into account interaction of internal forces for any type cross-section shape. The plastic designing with interaction is carried out according to the Simplex Method. There is possibility choosing the yield hypothesis according to Tresca or von Mises. It is possible to calculate the section properties and stresses of the effective crosssection according to [6] and [11] or [12]. Cross-section classification considers the available combination of internal forces.

The shape (geometry) of profile cross-sections under bending were modeled using linear or arc elements with thickness $2 \mathrm{~mm}$. All calculations were made according to $[6,11,12]$ and [13]. Because of preliminary types of this calculations, distortional buckling not was taken into account in analysis. As a static schema of the analysed elements, a self-supported single-span beam, was taken into account. The method of supporting beam at its ends allowed the beam to rotate freely at the horizontal axis and secured the ends of the beam against torsion. The beam was loaded by a continuous load, uniformly distributed, in and out of the plane of y-y main axis. Results of calculations were presented in Table 2 and Figure 4, 5 and 6.

Table 2: Results of calculations, elements without longitude stiffeners

\begin{tabular}{ccccc}
\hline & & channel & zeta & hat \\
& & $200 \times 2$ & $220 \times 2$ & $200 \times 2$ \\
\hline Agross & {$\left[\mathrm{cm}^{2}\right]$} & 7,56 & 7,52 & 14,49 \\
$*$ & - & 3 & 4 & 4 \\
$\mathrm{~W}_{y, \text { el }}$ & {$\left[\mathrm{cm}^{3}\right]$} & 45,88 & 46,44 & 81,91 \\
$\mathrm{~W}_{y, \text { eff }}$ & {$\left[\mathrm{cm}^{3}\right]$} & 45,88 & 45,62 & 54,72 \\
$\star \star$ & - & 4 & 4 & 4 \\
$\mathrm{~W}_{z, \text { el }}$ & {$\left[\mathrm{cm}^{3}\right]$} & 10,95 & 9,20 & 69,33 \\
$\mathrm{~W}_{z, \text { eff }}$ & {$\left[\mathrm{cm}^{3}\right]$} & 9,69 & 9,19 & 51,44 \\
$\mathrm{M}_{R d, y}$ & {$[\mathrm{kNm}]$} & 16,29 & 16,49 & 29,08 \\
$\mathrm{M}_{R d, y, \text { eff }}$ & {$[\mathrm{kNm}]$} & 16,29 & 16,20 & 19,43 \\
$\mathrm{M}_{R d, z}$ & {$[\mathrm{kNm}]$} & 3,89 & 3,27 & 24,61 \\
$\mathrm{M}_{R d, z, \text { eff }}$ & {$[\mathrm{kNm}]$} & 3,44 & 3,26 & 18,26 \\
$\star \star \star$ & {$[\mathrm{kg} / \mathrm{m}]$} & 5,93 & 5,90 & 11,37 \\
\hline
\end{tabular}

* - class of cross-section (bending by the main axis y-y),

$\star \star$ - class of cross-section (bending by the main axis $\mathrm{z}-\mathrm{z}$ ),

$\star \star \star$ - self-weight of profile 


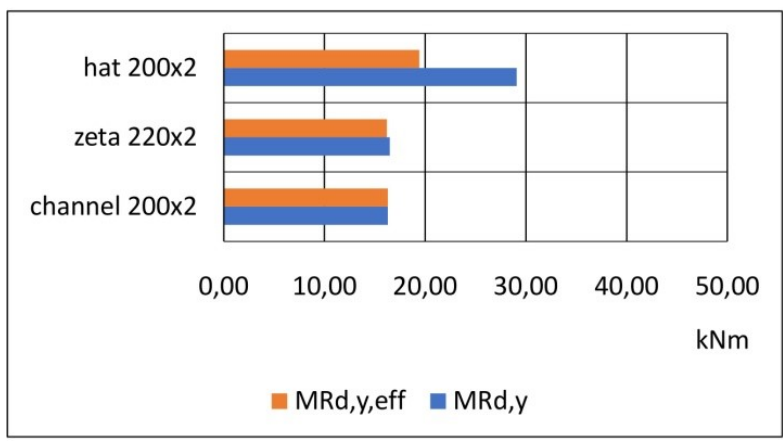

(a)

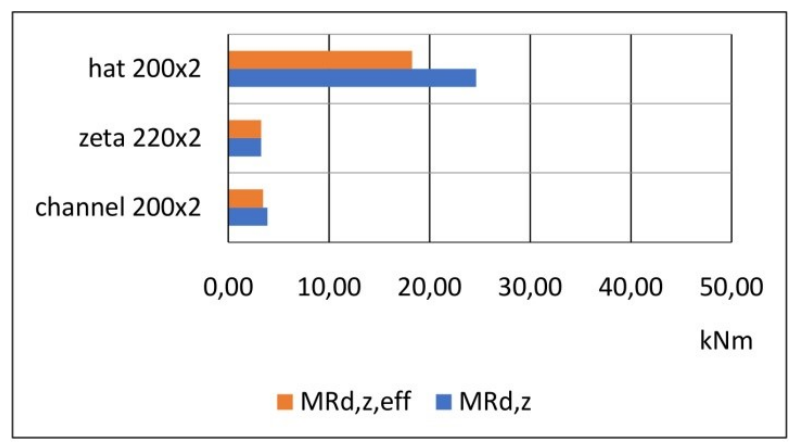

(b)

Figure 4: Resistance of cross-section in bending

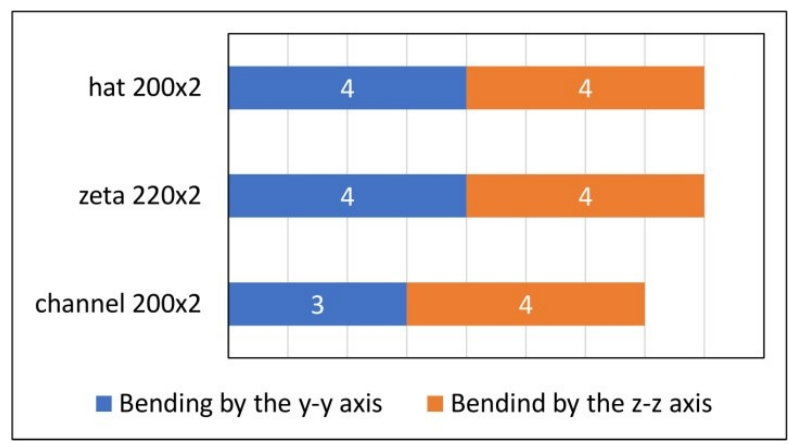

(a)

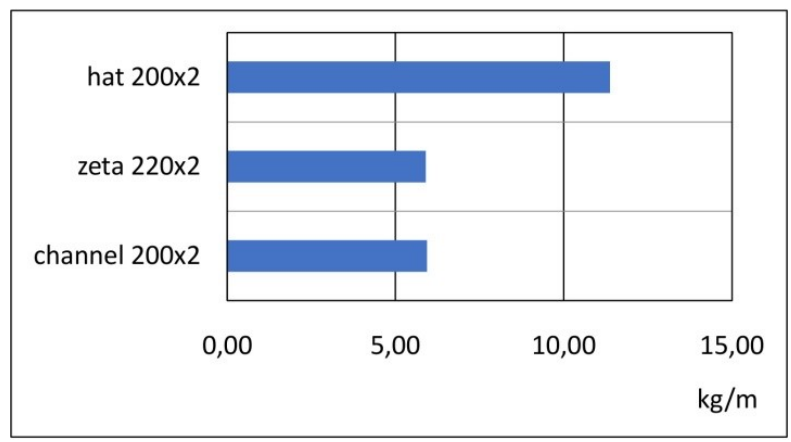

(b)

Figure 5: a) Class of cross-section, b) Self-weight of profiles

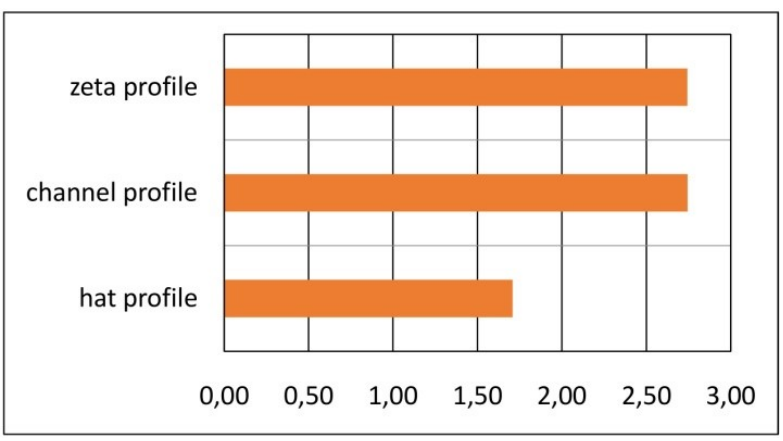

(a)

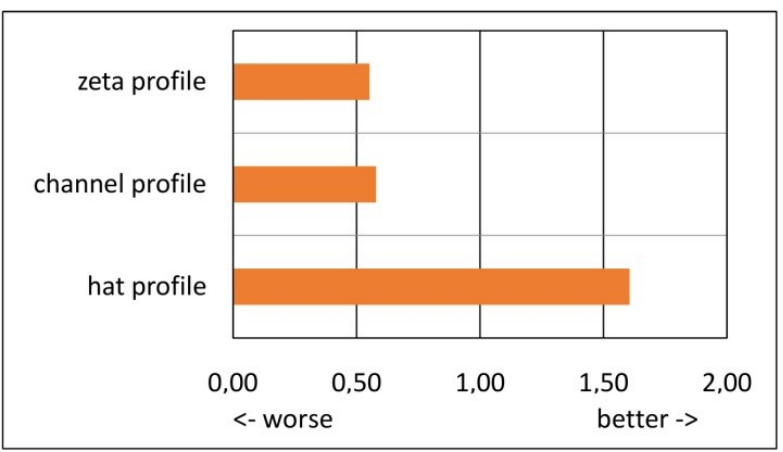

(b)

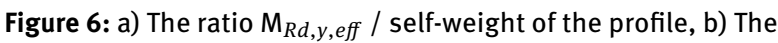
ratio $M_{R d, z, \text { eff }}$ / self-weight of the profile

The following results have been registered and saved during calculations:

- self-weight of profile

- class section of profile,

- geometricach characteristics gross cross-section (area, moments of inertia, section modulus and effective lengths of croos-setion plates),

- geometrical characteristics effective cross-section (as above),

- the extremal stress values of cross-section.

All this results were calculated automatically and next saved on on computer mass storage systems as a files with calculation data. Next, this data were imported to calculations software (calculation sheet). then they were sorted in tables and presented in the form of bar charts and exported to the word procesor.

Based on results of calculations, following conclusion can be made:

- In case of bending by the main axis $y-y$, only channel profile $200 \times 2$ cross-section is classified to 3 class; zeta $220 \times 2$ and hat $200 \times 2$ profiles counts to 4 class in bending. 
- In case of bending by the main axis $z-z$ all profiles are classified to 4 class in bending.

- The biggest difference between values $\mathrm{M}_{R d, y}$ and $\mathrm{M}_{R d, y, \text { eff }}$ or $\mathrm{M}_{R d, z}$ and $\mathrm{M}_{R d, z, \text { eff }}$ is for hat profiles; this is due to the fact that the cross section belongs to class 4 in bending. Making stiffeners on the wall of the profile can reduce the cross-section class and help to reduce the difference (increasing values of resistance of effective cross-section in bending $\mathrm{M}_{R d, y, \text { eff }}$ or $\mathrm{M}_{R d, z, \text { eff }}$ ).

- The value of the ratio of resistance of cross-section in bending by the main axis $y$-y to self-weight of profile is rather adverse for the hat profiles - because of greater self-weight these profile than zeta and channel profiles, and reduction of resistance due to class 4 cross-section. But in case of bending by the main axis $\mathrm{z}-\mathrm{z}$ axis of cross-section, the value of this coefficient is more favorable than for other profiles.

- All conclusions provided above, may be the reason to make longitudinal profile stiffeners, to reduce class of cross-section and increasing their bending strength values.

\subsubsection{Influence of numbers of longitude stiffeners on geometrical characteristics of hat cross-sections}

Taking into account conclusions written above, the second stage analysis was made. In this calculations, influence of numbers of stiffeners on geometrical characteristics and resistance of hat cross-sections were obtained. Four types of profiles were taken into account, Figure 7: a)

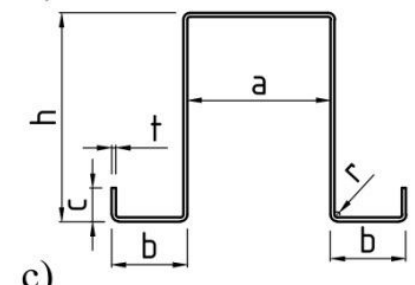

b)

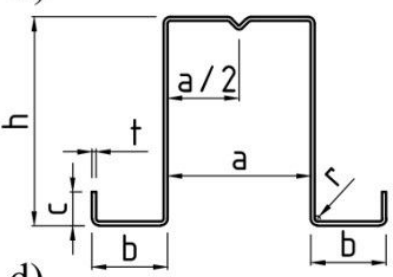

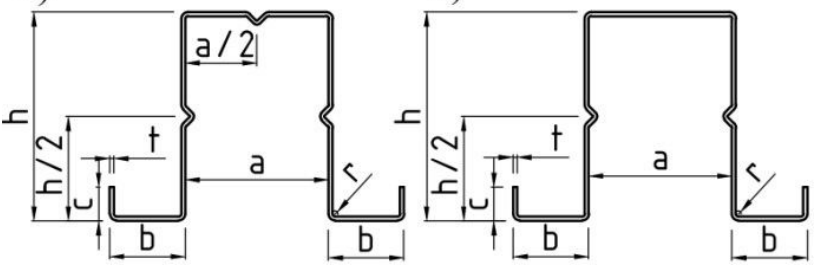

Figure 7: View of analysed hat profiles: a) cross-section without longitudinal stiffeners, b) cross-section with stiffener on upper chord, c) cross-section with stiffeners on webs, d) cross-section with stiffeners on upper chord and webs
- profiles without longitudinal stiffeners,

- profiles with stiffener on upper chord,

- profiles with stiffeners on webs,

- profiles with stiffeners on upper chord and webs.

The resistance in bending in and out of plane of $y-y$ main axis of cross-section were determined and compared.

As previously, all geometrical characteristics of crosssection of hat profiles and class of cross-section were calculated using SHAPE-THIN Dlubal software. Results of calculations were presented in Table 3. View of effective crosssection area of analysed profiles was presented on Figure 8 and 9.

Table 3: Results of calculations, hat profiles with longitude stiffeners

\begin{tabular}{|c|c|c|c|c|}
\hline & $\begin{array}{c}\text { hat } \\
200 \times 2\end{array}$ & $\begin{array}{c}\text { hat } \\
200 \times 2 U\end{array}$ & $\begin{array}{c}\text { hat } \\
200 \times 2 W\end{array}$ & $\begin{array}{c}\text { hat } \\
200 \times 2 U W\end{array}$ \\
\hline$A_{\text {gross }}\left[\mathrm{cm}^{2}\right]$ & 14,49 & 14,62 & 14,75 & 14,88 \\
\hline * & 4 & 4 & 4 & 3 \\
\hline $\mathrm{W}_{y, e l}\left[\mathrm{~cm}^{3}\right]$ & 81,91 & 83,32 & 82,00 & 83,41 \\
\hline $\mathrm{w}_{y, \text { eff }}\left[\mathrm{cm}^{3}\right]$ & 54,72 & 82,48 & 59,84 & 83,41 \\
\hline ** & 4 & 4 & 4 & 4 \\
\hline $\mathrm{W}_{z, e l}\left[\mathrm{~cm}^{3}\right]$ & 69,33 & 69,33 & 69,76 & 69,76 \\
\hline $\mathrm{W}_{z, \text { eff }}\left[\mathrm{cm}^{3}\right]$ & 51,44 & 51,50 & 63,92 & 63,94 \\
\hline $\mathrm{M}_{R d, y}[\mathrm{kNm}]$ & 29,08 & 29,58 & 29,11 & 29,61 \\
\hline $\mathrm{M}_{R d, y, \text { eff }}[\mathrm{kNm}]$ & 19,43 & 29,28 & 21,24 & 29,61 \\
\hline $\mathrm{M}_{R d, z}[\mathrm{kNm}]$ & 24,61 & 24,61 & 24,76 & 24,76 \\
\hline $\mathrm{M}_{R d, z, \text { eff }}[\mathrm{kNm}]$ & 18,26 & 18,28 & 22,69 & 22,70 \\
\hline$\star \star \star[\mathrm{kg} / \mathrm{m}]$ & 11,37 & 11,48 & 11,58 & 11,68 \\
\hline
\end{tabular}

* - class of cross-section (bending by the main axis $y-y$ ),

$\star \star$ - class of cross-section (bending by the main axis $\mathrm{z}-\mathrm{z}$ ),

$\star \star \star-$ self-weight of profile

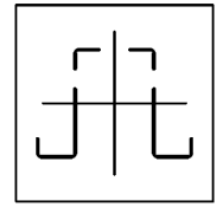

(a)

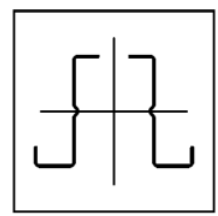

(c)

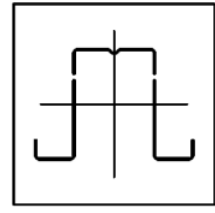

(b)

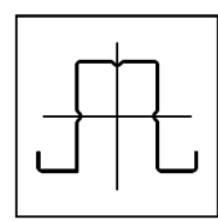

(d)
Figure 8: View of effective cross-section area of analysed hat profiles - bending by the main axis $y$-y: a) profile without longitudinal stiffeners, b) profile with stiffener on upper chord, c) profile with stiffeners on webs, d) profile with stiffeners on upper chord and webs 


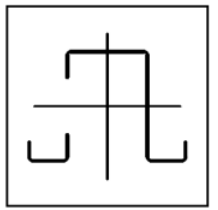

(a)

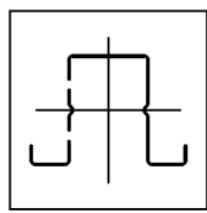

(c)

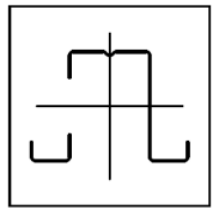

(b)

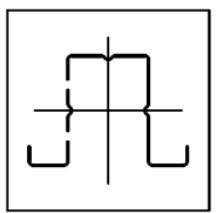

(d)
Figure 9: View of effective cross-section area of analysed hat profiles - bending by the main axis z-z: a) profile without longitudinal stiffeners, b) profile with stiffener on upper chord, c) profile with stiffeners on webs, d) profile with stiffeners on upper chord and webs

Based on results of calculations, following conclusions can be made:

- Making longitudinal stiffeners in a very small way increases the weight of the profile - no more than $3 \%$.

- In case of bending by the main axis y-y of crosssection, stiffeners made only on upper chord or only on webs do not changing class of cross-section. Just making stiffeners together on upper chord and webs, reduced class of cross-section in bending.

- In case of bending by the main axis z-z of crosssection, stiffeners made on upper chord and on webs not changing class of cross-section. Cross-section still remains in class 4 in bending.

- Making of longitudinal stiffeners causes an increasing of effective section module of profiles and its bending resistance, Figure 10. In case profiles making of $2 \mathrm{~mm}$ sheet thickness, the most effective is making stiffeners on webs or webs and upper chord - this causes an increase the value of resistance of bending by the main axis y-y about $50 \%$.

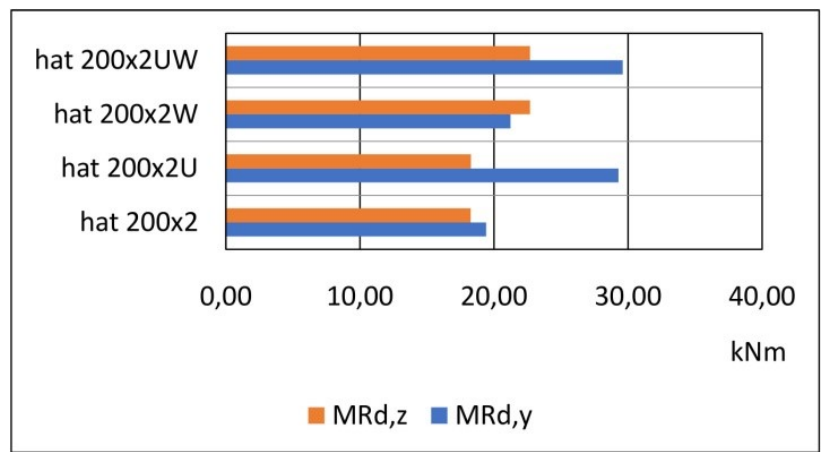

(a)

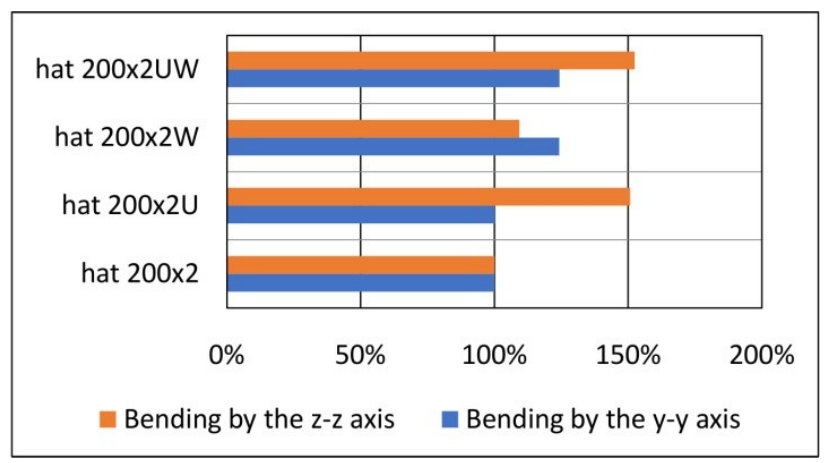

(b)

Figure 10: a) Resistance of cross-section in bending, b) percentage increase bending capacity of cross-section in relation to the nonstiffened profile

\subsubsection{Comparison of geometrical characteristics of cross-sections of hat, channel and zeta profiles with longitudinal stiffeners}

In the third part of calculations comparative analysis was carried out. In this analysis three types of cross-sections were compared: hat profiles, channel profiles and zeta profiles with stiffeners on webs. The stiffeners on upper chord of profiles were neglected. It was due to the difficulty of fixing the roof sheeting to the upper chord of purlin with its stiffeners. Like previously, two kind of load were taking into consideration: bending by the main axis $y-y$ or $z-z$ of cross-section. Due to the preliminary nature of calculations, as a static schema of the analysed elements, a singlespan beam, self-supported was taken into account. View of effective cross-section of profiles (in both cases of the load) was presented on Figure 9 and 11. Results of analysis were presented in Table 4 and Figure 12. 


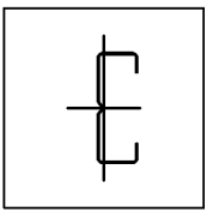

(a)

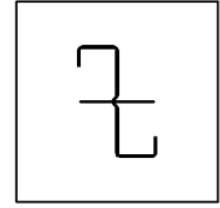

(c)

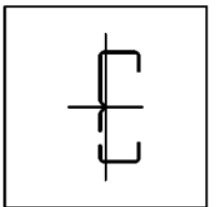

(b)

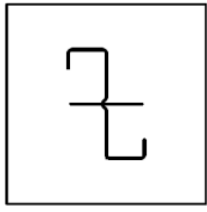

(d)
Figure 11: View of effective cross-section area of analysed profiles with stiffener on the web: a) channel profile, bending by the main axis $y-y, b)$ channel profile, bending by the main axis z-z, c) zeta profile, bending by the main axis $y-y, d)$ zeta profile, bending by the main axis $z-z$

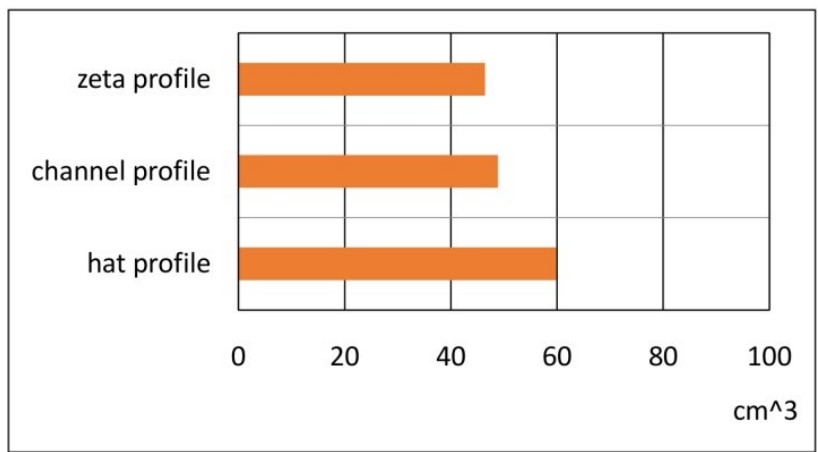

(a)

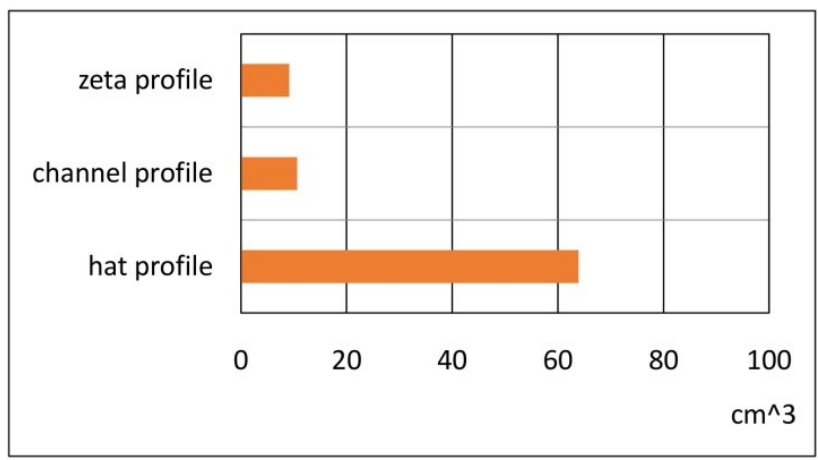

(b)

Figure 12: a) Section modulus of the effective cross-section with regard to the $y$-y axis $w_{y, \text { eff }}$, b) Section modulus of the effective cross-section with regard to the $z-z$ axis $W_{z}$,eff
Table 4: Results of calculations, hat profiles with longitude stiffeners

\begin{tabular}{ccccc}
\hline & & hat & channel & zeta \\
& & $200 \times 2 \mathrm{~W}$ & $200 \times 2 \mathrm{~W}$ & $220 \times 2 \mathrm{~W}$ \\
\hline$*$ & - & 4 & 3 & 3 \\
$\mathrm{~W}_{y, \text { eff }}$ & {$\left[\mathrm{cm}^{3}\right]$} & 59,84 & 48,89 & 46,47 \\
$\star \star$ & - & 4 & 4 & 3 \\
$\mathrm{~W}_{z, \text { eff }}$ & {$\left[\mathrm{cm}^{3}\right]$} & 63,92 & 10,64 & 9,17 \\
$\mathrm{M}_{R d, y, \text { eff }}$ & {$[\mathrm{kNm}]$} & 21,24 & 17,36 & 16,64 \\
$\mathrm{M}_{R d, z, \text { eff }}$ & {$[\mathrm{kNm}]$} & 22,69 & 3,78 & 3,26 \\
$\star \star \star *$ & {$[\mathrm{~kg} / \mathrm{m}]$} & 11,58 & 6,03 & 6,00 \\
\hline
\end{tabular}

* - class of cross-section (bending by the main axis y-y),

$\star \star$ - class of cross-section (bending by the main axis z-z),

$\star \star \star$ - self-weight of profile

\section{Final conclusions}

Based on the results of the calculations described above, the following main conclusion can be formulated:

- The self-weight of purlins made of hat profiles is about two times more than channel and zeta profiles with similar geometrical dimensions (the high of the profile).

- Purlins made of hat profiles are characterized by a relatively high bending resistance with bi-axial bending. For this reason, it is recommended to use them in roof structure with a large roof slope angle.

- Making of longitudinal stiffeners causes a decreasing of class of cross-section and an increasing of effective section module of profiles and its bending resistance.

- Due to the difficulty of fixing the roof sheeting to the upper chord of purlin, making longitude stiffener on this part of element can be not recommended for execution.

- Making only one longitude stiffener on webs of hat and channel profiles may be ineffective. In this types of profiles (especially for greater heights), it may be necessary making two stiffeners to in order to improve the load capacity of cross section in bending, see. Table 4 and Figure 12.

- Finally it can be said that cold-formed steel purlins with hat cross-section can be an alternative to purlins with channel and zeta cross-sections and hot-rolled members.

The above-mentioned conclusions relate to purlins, which are secured against lateral torsional buckling with a roof sheeting plate. In the case of lack of protection against 
lateral torsional buckling and a larger degree of roof slope, hat cross-sections may be more advantageous. However, this requires further calculations. The distortional buckling, global stability and the other static schema of purlins should be taken into consideration in further calculations.

The article was developed as part of the research project implemented in cooperation with the Rzeszów University of Technology and the company FPUH KOBEX, as part of the activity: Regional Operational Program of the Podkarpackie Voivodeship for 2014-2020, Priority axis: I Competitive and innovative economy, Measure: 1.2 Industrial research, development works and their implementation, Project type: Research and Development B+R.

\section{References}

[1] Wang L, Young B. Cold-Formed Steel Channel Sections with Web Stiffeners Subjected to Local and Distortional Buckling - Part I: Tests and Finite Elements Analysis, International Specialty Conference on Cold-Formed Steel Structures. 1., 2014.

[2] Cucu V, Constantin D, Buliga DI. Structural efficiency of coldformed steel purlins, International Conference Knowledge-Based Organization Vol. XXI. No 3., 2015, https://doi.org/10.1515/kbo2015-0137.

[3] Tan J, Susila A. Flexural strength performance and buckling mode prediction of cold-formed steel (C section). Procedia Eng. 2015;125:979-86.
[4] Papangelis JP, Hancock GJ, Trahair NS. Computer Design of ColdFormed C- and Z-Section Purlins. J Construct Steel Res. 1998 Apr-Jun;46(1-3):169-71.

[5] Qasim TM, Al-Zaidee SR. Experimental Investigation for Non and Partially Composite Cold-Formed Steel Floor Beams, Civil. Eng J (NY). •••;5(6): https://doi.org/10.28991/cej-2019-03091341.

[6] EN 1993-1-3: Eurocode 3: Design of steel structures - Part 1-3: General rules - Supplementary rules for cold-formed members and sheeting. European Committee for Standardization, Brussels, 2006

[7] Bródka J, Broniewicz M, Giżejowski M. Ksztattowniki gięte. Poradnik projektanta. Rzeszów: Polskie Wydawnictwo Techniczne; 2006.

[8] Bródka J. Łubiński M., Lekkie konstrukcje stalowe. Warszawa: Arkady; 1978.

[9] Abdi R., Yazdi N. A., Effects of aspect ratio and plate thickness on the behavior of unstiffened steel-plate shear walls with pinned and rigid connections, Journal Article published $4 \mathrm{Jul}$ 2018 in Civil Engineering Journal volume 4 issue 6 on page 1383, https://doi.org/https://doi.org/10.28991/cej-0309180.

[10] Dlubal SH. https://www.dlubal.com/pl

[11] EN 1993-1-5 (2006): Eurocode 3: Design of steel structures - Part 1-5: General rules - Plated structural elements. European Committee for Standardization, Brussels.

[12] EN 1993-1-1: Eurocode 3: Design of steel structures - Part 1-1: General rules for buildings. European Committee for Standardization, Brussels, 2005

[13] ECCS Technical Committee 7 Cold-formed Steel Worked examples according to EN 1993-1-3 Eurocode 3, Part 1-3 